International Conference on Business Research

University of Moratuwa, Moratuwa, Sri Lanka

June 13, 2018, 70-80.

DOI: https://doi.org/10.31705/ICBR.2018.9

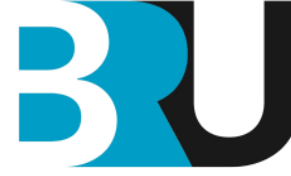

BUSINESS RESEARCH UNIT

FACULTY OF BUSINESS

UNIVERSITY OF MORATUWA

\title{
Factors determining the intention to adopt cloud computing by finance companies in Sri Lanka
}

\author{
C. H. M Dakshina Tharanga ${ }^{{ }^{*}}$ and Indika Perera ${ }^{2}$ \\ ${ }^{1}$ Department of Management of Technology, Faculty of Business, University of \\ Moratuwa, Sri Lanka \\ ${ }^{2}$ Department of Computer science, Faculty of Engineering, University of \\ Moratuwa, Sri Lanka
}

\begin{abstract}
Cloud computing has become the most evolving technological innovation that reduces the processing cost while increasing the availability, flexibility, reliability and processing throughout. Though this is an emerging technology and the rest of the worlds' finance companies are implementing it, Sri Lanka's finance companies have not gained the competitive advantage of adopting cloud technology as yet. This study therefore has made significant efforts on analysing what factors determine the intention to adopt cloud computing by the finance companies of Sri Lanka. Selective factors from Innovation Diffusion Theory and Technology-Organization-Environment framework such as relative advantage, compatibility, complexity, trialability, security, top management support and technology readiness were considered. From the total of 45 licensed finance companies in Sri Lanka, 35 companies were targeted to collect primary data. Survey-based questionnaire method was used to collect data. A statistical analysis was carried out using IBM SPSS Statistical Software v.23, and hypotheses were tested based on the results of multiple regression. According to the regression model, it is recognised that relative advantage and compatibility are significant factors which predict the adoption of cloud computing. It has also analyzed the moderating impact on finance resource allocation on the relationship between independent variables (seven factors) and adoption of cloud computing. Findings suggest that financial resource allocation would not have a significant impact on the model's ability to determine adoption of cloud computing.
\end{abstract}

Keywords: cloud computing, technology adoption, relative advantage, compatibility, financial resource allocation. 


\section{Introduction}

\subsection{Research background}

Nowadays, Technology is playing a crucial role in the finance sector by streamlining the front-end to back-end processes, offering lower cost, value added and customized solutions. In today's highly complex and competitive business environment, organisations are perceived on achieving competitive advantages in terms of increasing productivity through effective and efficient utilisation of resources, increasing profitability and reducing costs (Misra \& Mondal, 2011). According to Gill (2011) Information Technology, specially the up-to-date technologies plays a vital role in increasing effective and efficient utilisation of resources, reduce costs, improve the bottom line of the operations and sustain competitive advantages. However, the use of advanced information technologies has increasingly become time consuming and expensive (Bayo-Moriones \& Lera-Lopez, 2007) where the cloud computing becomes the most evolving technological innovation that reduces the processing cost while increasing the availability, flexibility, reliability and processing throughout (Oliveira, Thoman \& Espadanal, 2014). According to Mell and Grance (2011) cloud computing also provides benefits in terms of broad network access, rapid elasticity and resource pooling.

The adoption of cloud computing like any other technology adoption requires a thorough understanding about the relative advantages, costs associated with and the challenges involved in the implementation process. Moreover, even though the cloud computing is implemented by the many sectors in the international context, it is quite a new topic for the Sri Lankan business sector. Though this is an emerging technology and rest of the worlds' finance companies are being implemented, Sri Lanka's finance companies have not gain the competitive benefits of adopting cloud technology yet. Moreover, it is also noted that there can be many underlying reasons influencing the adoption of cloud computing where most of the research studies only focused on the security concerns which is not enough to determine the adoption of cloud computing. Existing research studies have paid attention on potential applications (Rochwerger et al, 2009), computing architecture (Rochwerger et al, 2009) and costs and benefits of cloud technology (Assuncao, Costanzo \& Buyya, 2009). There are only few studies that investigate the adoption of cloud technology in Sri Lankan context and there is no evidence particular to the finance companies' adoptability of cloud computing. Therefore, this research study is made significant efforts to find answers to the research question "What factors determine the intention to adopt the cloud computing by the finance companies of Sri Lanka?"

\subsection{Scope of the research}

This research study is focused on analysing factors determining the intention to adopt the cloud computing of finance companies in Sri Lanka. The scope is narrowed down to a sample of 35 licensed finance companies in Sri Lanka. Among the literature, it is found that IDT (Innovation diffusion theory) and TOE (Technology, Organisation and Environment) theories discuss the factors 
influencing the adoption of technology in the perspectives of the organisational level (Low, Chen and $\mathrm{Wu}, 2011$ ). The scope of the research is limited to factors such as 'relative advantage, complexity, compatibility, trialability' as technology factors and 'top management support, technology readiness' as organisational factors and added the 'security concerns' to the framework in order to make it feasible for the Sri Lankan finance companies.

\subsection{Research aim and objectives}

Main aim of undertaking this study is "to analyse the factors deciding the suitability of cloud computing in the finance companies in Sri Lanka". In addition to that, this research paper sought to achieve the following objectives;

1. To assess the benefits of cloud computing to the finance companies in Sri Lanka

2. To determine the factors influencing the adoption of cloud computing by the finance companies in Sri Lankan

3. To analyse the impact of these factors to adopt cloud computing by the finance companies in Sri Lanka

4. To provide recommendations for the finance sector to influence the intention to adopt cloud computing

\section{Literature review}

As cited by Mell and Grance (2011) NIST defines cloud computing as a "model for enabling ubiquitous, convenient, on-demand network access to a shared pool of configurable computing resources (e.g., networks, servers, storage, applications and services) that can be rapidly provisioned and released with minimal management effort or service provider interaction. As Foster, Zhao, Raico and Lu (2008) posit, cloud computing is different from other computing paradigms such as grid computing in terms of abstraction, applications, data model, computer model, business model, programming model and security. In the existing literature, most of the research studies provide the knowledge about cloud computing and improve the reader's understanding about cloud computing (Grossman, 2009). Moreover, many researchers have evaluated the factors influencing cloud computing adoption in different industry perspectives.

Researchers such as Oliveira and Martins (2011) and Baker (2012) made attempts to apply TOE model to determine the factors and found that relative advantage, complexity and compatibility as technological factors; top management support, firm size and technology readiness as organizational factors; trade partner pressure and competitive pressure as environmental factors; that significantly impact on the firm's intention to adopt cloud computing. Rieger, Gewald and Schumacher (2013) studied the understanding of the factors associated with adoption of cloud computing in the banking sector considering the factors proposed by TOE framework. According to the findings, financial benefits found to be the most significant perceived benefit, whereas regulations of the government considered as the most significant risk by the management. Moreover, compliance 
requirements, government regulations security requirements and technology supporting infrastructure are the most significant factors influencing the adoption decision of cloud computing.

Fernando (2017) conducted a research to understand cloud computing adoption factors by IT sector in Sri Lanka considering the theory of innovation diffusion, especially the TOE framework covering technology, organisational and environmental factors. Findings concluded that technology readiness, top management support, trialability, complexity, compatibility, relative advantage and innovativeness of the decision maker as the most significant concerns influencing the adoption of cloud computing by IT companies in Sri Lanka. Ayoobkhan and Asirvatham (2017) analysed cloud computing in the healthcare sector in Colombo district private hospitals in Sri Lanka and revealed that technology factors, organisation factors and environmental factors significantly impact the decision to adopt cloud computing.

\section{Methodology}

\subsection{Conceptual framework}

Innovation Diffusion Theory considers factors such as relative advantage, compatibility, complexity, trialability and observability in understanding the organisations adoptability of a technology (Rogers, 2003). TOE framework identifies three contexts namely technological, organisational and environmental which determine the adoptability of a technology by an organisation. Here, technology factor includes relative advantage, complexity and compatibility, and organisational factors include top management support, technology readiness and firm size, whereas environmental factors includes competitive pressure and trading partner pressure. The present study has used some of the factors proposed by these two models adding the security concerns to the framework in order to make it feasible for the Sri Lankan finance companies. Moreover, financial resource allocation is considered as a moderator variable which controls the association between the independent variables and dependent variable. Figure 1 presents the conceptual model.

\subsection{Research hypotheses}

H1: Relative advantage of cloud computing positively impacts the finance companies' adoption of cloud computing

H2: Complexity of cloud computing negatively impacts on the finance companies' adoption of cloud computing

H3: Compatibility of cloud computing positively impacts on the finance companies' adoption of cloud computing

H4: Trialability of cloud computing positively impact the finance companies' adoption of cloud computing

H5: Security of cloud computing positively impacts on the finance companies' adoption of cloud computing

H6: Top management support positively impacts the finance companies' adoption of cloud computing 
H7: Technology readiness positively impacts on the finance companies' adoption of cloud computing

H8: Financial resource allocation moderates the association between independent variables (relative advantage, complexity, compatibility, trialability, security, top management support and technology readiness) and the adoption of cloud computing

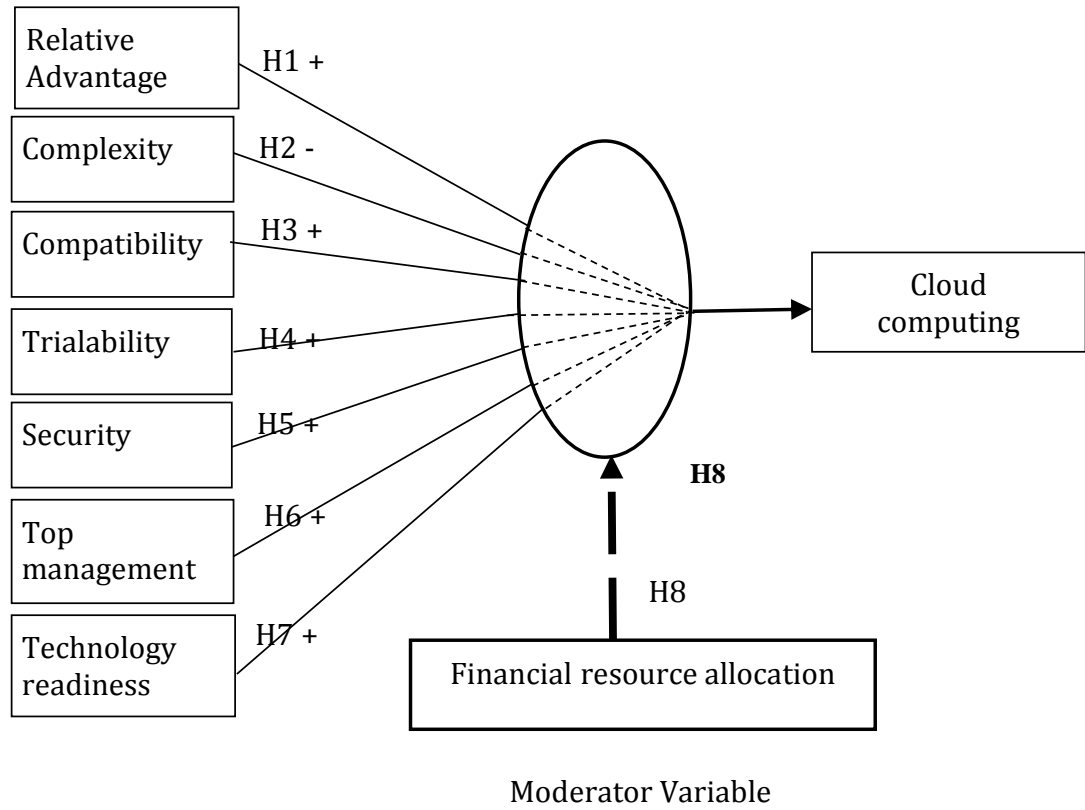

Figure 1. Conceptual framework

\subsection{Research design}

From the total of 45 licensed finance companies in Sri Lanka, 35 companies were selected to collect primary data due to limitation of access of the entire population (Data sensitivity, Security and Internal policies). Survey-based questionnaire method was occupied and standardised data was collected. These data were analysed and closed-ended questions were measured by five-point Likert scale. Using IBM SPSS Statistical Software v.23, a statistical analysis was carried out and hypotheses were tested based on the results of multiple linear regression. 


\section{Results}

\subsection{Descriptive analysis}

This study collected data from a sample of 35 finance companies in Sri Lanka and found that 25 firms, which is the majority of the sample believe that cloud will bring values to their firm, while the rest of firms did not know whether cloud will bring value to their company or not. Almost all the finance firms in the sample were aware about the competitive advantages of cloud computing including avoiding capital expenditure on IT infrastructure, flexibility, capability of scaling up resource requirements, eliminating costs in maintaining data centres, time saving capability as well as IT optimisation, increasing business performance capacity and controlling marginal profits and costs. However, there are some finance firms in the sample which were not aware about some of the benefits of cloud, especially its capability of assessing feasibility of the operations and profitability, ability to control marginal profit and marginal costs and its flexibility. As per the findings, it is also noted that relative advantage recorded the highest mean value among the seven factors which is very close to 4 . This evidenced nearly at higher level and the sample is agreed that cloud brings relative advantages such as speed of business communication, better customer communication, cost reduction, flexibility and mobility.

\subsection{Results of the multiple linear regression}

According to the regression model, it is recognised that relative advantage and the compatibility as the significant factors which predict the adoption of cloud computing. Complexity, trialability, security, top management support and technology readiness would not have a significant impact on the model's ability to predict the adoption of cloud computing.

Table 1. Regression model

\begin{tabular}{ccccc}
\hline Model & $\mathrm{R}$ & R Square & Adjusted R Square & l. Error of the Estimate \\
\hline 1 & $.766^{\mathrm{a}}$ & .586 & .574 & .37786 \\
2 & $.830^{\mathrm{b}}$ & .668 & .669 & .33288 \\
\hline
\end{tabular}

a. Predictors: (Constant), Relative advantage

b. Predictors: (Constant), Relative advantage, compatibility

The model 1 includes only the relative advantage which has the highest correlation value among other variables. The $r$ value of 00.766 indicates the correlation between relative advantage and adoption of cloud computing, reflecting a strongly positive relationship between relative advantage and adoption of cloud computing. The adjusted r square of 00.574 explains that $57.4 \%$ of adoption of cloud computing is determined by relative advantage alone. The second model added compatibility together with relative advantage. The $r$ value of 00.830 explains a strongly positive correlation between the model 2 (combination of relative advantage and compatibility) and adoption of cloud computing. The adjusted $r$ square of 00.669 explains 
that relative advantage and compatibility together are accountable for $66.9 \%$ of the adoption of cloud computing.

In model one, only the relative advantage has a significant impact over adoption of cloud computing, and the unstandardized slope of 00.907 tells that every additional increase of relative advantage results an increase of 00.907 points of adoption of cloud computing. The sig. value of 00.000 indicates a high significance. In model 2, both relative advantage and compatibility have significant impacts over the adoption of cloud computing. The unstandardized slope of 00.562 explains that additional increase of relative advantage results in an increase of 00.562 of adoption of cloud computing and the slope of 00.365 indicates that every additional apply of compatibility increases the adoption of cloud computing by 00.396 points. These two also got sig. values of 00.001 and 00.003 which are lower than 00.050 . These results justify that both relative advantage and compatibility are good predictors of the adoption of cloud computing than other variables as these two are having slopes that are not equal to zero in the sample.

Table 2. Coefficient

\begin{tabular}{llccccc}
\hline Model & & \multicolumn{2}{c}{$\begin{array}{c}\text { Unstandardized } \\
\text { Coefficients }\end{array}$} & \multirow{2}{*}{$\begin{array}{c}\text { Standardized } \\
\text { Coefficients } \\
\text { (Beta) }\end{array}$} & $t$ & Sig. \\
\cline { 3 - 5 } & \multicolumn{1}{c}{ B } & Std. Error & & \\
\hline 1 & (Constant) & -.060 & .523 & & -.114 & .910 \\
& Relative & .907 & .133 & .766 & 6.835 & .000 \\
& Advantage & & & & & \\
\hline 2 & (Constant) & -.057 & .460 & & -.124 & .902 \\
& $\begin{array}{l}\text { Relative } \\
\text { Advantage }\end{array}$ & .562 & .158 & .474 & 3.557 & .001 \\
& Compatibility & .365 & .113 & .433 & 3.244 & .003 \\
\hline
\end{tabular}

Dependent variable: Cloud adoption

\subsection{Moderating impact}

It is recognized that only the relative advantage and compatibility variables have a significant impact on the adoption of cloud computing (H1 and H2). Even though moderating variables were entered into the model, they would not have been a significant impact on the models ability to determine the adoption of cloud computing.

\section{Discussion}

According to the analysis, it is found that among the seven factors only relative advantage and the compatibility as the significant factors that predict the adoption of cloud computing. Other factors including complexity, trialability, security, top management support and technology readiness, do not make any significant impact on the finance companies' decision to adopt cloud computing. Relative advantage and compatibility together are 
accountable for $66.9 \%$ of the adoption of cloud computing. This finding is more similar to the findings of Mumcu (2004) who confirmed that compatibility and the relative advantages are the two most significant factors that positively correlated with the technology adoption. In contrast to the evidence of the present study, literature evidenced that complexity (Sahin, 2006); trialability (Ntemana \& Olatokun, 2012), security (Respschkaeger et al., 2012), top management support (Gutierrez et al., 2015) and technology readiness (Laforet, 2011) also significantly influence the intention to adopt cloud computing.

\section{Conclusion, implications and recommendations}

\subsection{Conclusion}

The prime aim of undertaking this research study is to analyse the factors determining the intention to adopt cloud computing by finance companies in Sri Lanka. Even though cloud brings many sustainable competitive advantages, finance companies in Sri Lanka have not yet adopted this technology. The main reason behind undertaking this research study was analysing what factors determine the finance companies' adoption of cloud computing. There are many different factors suggested by the literature through different models, frameworks and empirical evidence However, the present study considered seven factors namely relative advantage, complexity, compatibility, trialability and security (technology factors), top management support and technology readiness (organisational factors).

Multiple regression is analysed to understand the impact of these factors on the intention to adopt cloud computing. According to the analysis, it is found that only relative advantage and the compatibility are the significant factors that predict the adoption of cloud computing. Other factors including complexity, trialability, security, top management support and technology readiness do not make any significant impact on the finance companies' decision to adopt cloud computing. It also analysed the moderating effect of financial resource allocation on the impact of each of these factors and cloud computing. However, as per the multiple regression results, moderating variables of relative advantage, compatibility, complexity, trialability, security, top management and technology readiness would not have significant impact on the models ability to determine the adoption of cloud computing.

Based on the findings, it can be concluded that among the factors, relative advantage, compatibility, complexity, trialability, security, top management and technology readiness, only relative advantage and compatibility significantly impact on the finance companies' intention to adopt cloud computing, and other factors do not have any statistically significant impact on the intention to adopt cloud computing. In addition to that, it is confirmed that financial resource allocation does not have a significant moderating impact over the association between these factors and the intention to adopt cloud computing by the finance companies. 


\subsection{Implications}

It is noted that in Sri Lankan literature, there are lack of evidence regarding the adoption of cloud computing by finance companies, and the findings of this study therefore, minimise this research gap. This study mainly has been undertaken by developing a conceptual model using different factors from different theoretical models of technology adoption. These factors were linked with the adoption of cloud computing and developed a novel model for the purpose of this study. Therefore, this model can be used by the future researchers and scholars to study the factors determining the adoption of cloud computing.

Moreover, findings of this study also have practical implications to the finance companies in Sri Lanka. This study covered many areas of cloud computing including its benefits, risks, challenges and more importantly different factors influencing the adoption of cloud computing. These findings enable the finance companies to understand the relative advantages of cloud computing and factors influencing the adoption. So that they can effectively implement cloud computing for their operations and achieve competitive advantages in the competitive business environment.

\subsection{Recommendations}

As per the findings of the present study, financial resource allocation does not moderate the decision to adopt cloud computing. The top management support and technology readiness of the company further do not impact the intention to adopt cloud computing. Therefore, having considered the benefits and relative advantages of cloud computing, it is recommended for the finance companies to adopt cloud computing and achieve the competitive advantages in the industry. Also it is suggested for the finance companies to consider the relative advantages of cloud computing and make a thorough analysis regarding all of its benefits, risks and challenges in deploying the cloud computing service. Further it is very important to align their business needs, internal systems, policies, procedures, beliefs and value system as well as the employee behavioural conditions with the cloud computing service in order to achieve the maximum benefits.

\section{References}

Assuncao, M.D., Costanzo, A. \& Buyya, R. (2009). Evaluating the cost-benefit of using cloud computing to extend the capacity of clusters. Proceedings of the 18th ACM International Symposium on High Performance Distributed Computing, Munich, 11-13 June, 141-150.

Ayoobkhan, A.L.M. \& Asirvatham, D. (2017). Adoption of cloud computing services in healthcare section: special attention to private hospitals in Colombo District, Sri Lanka. Current Journal of Applied Science and Technology, 23(2), 1-10.

Baker, J. (2012). The technology-organization-environment framework. Information Systems Theory, 28, 231-245. 
Bayo-Moriones, A. \& Lera-Lopez, F. (2007). A firm-level analysis of determinants of ICT adoption in Spain. Technovation, 27, 352-366.

Fernando, D.C. (2017). Critical success factors affecting public cloud computing business within Sri Lanka. Unpublished Theses. University of Moratuwa, Sri Lanka.

Foster, I., Zhao, Y., Raico, I. \& Lu, S. (2008). Cloud computing and grid computing 360-degree compared. Grid Computing Environments Workshop, GCE '08, 1-10.

Gill, R. (2011). Why cloud computing matters to finance. Strategic Finance, 92, 43-47.

Grossman, R. L. (2009). The case for cloud computing. IT Professionals, 11(2), 23-27.

Gutierrez, A., Boukrami, E., \& Lumsden, R. (2015). Technological, organisational and environmental factors influencing managers' decision to adopt cloud computing in the UK. Journal of Enterprise Information Management, 28(6), 788-807.

Laforet, S. (2011). A framework of organisational innovation and outcomes in SMEs. International Journal of Entrepreneurial Behaviour and Research, 17(4), 380-408.

Low, C., Chen, Y., \& Wu, M. (2011). Understanding the determinants of cloud computing adoption. Industrial Management \& Data Systems, 111(7), 1006-1023.

Mell, P., \& Grance, T. (2011). The NIST Definition of Cloud Computing. Gaithersburg. Computer Security Division Information Technology Laboratory National Institute of Standards and Technology. Retrieved from https://www.nist.gov/publications/nist-definition-cloud-computing.

Misra, S. C. \& Mondal, A. (2011). Identification of a company's suitability for the adoption of cloud computing and modeling its corresponding return on investment. Mathematical and Computer Modelling, 53, 504-521

Mumcu, F. K. (2004). Diffusion of information and communication technologies in vocational and technical schools. Master's thesis. Department of Computer Education and Instructional Technologies, Hacettepe University, Ankara, Turkey.

Ntemana, T. J., \& Okatokun, W. (2012). Analysing the influence of diffusion of innovation attributes on lecturers' attitudes towards information and communication technologies. An Interdisciplinary Journal on Humans in ICT Environments, 8(2), 179-197

Oliveira, T. \& Martins, M. F. (2011). Literature review of information technology adoption models at firm level. Electronic Journal Information Systems Evaluation, 14(1), 110-121.

Repschlaeger, J., Wind, S., Zarnekow, R., Turowski, K. (2012). A reference guide to cloud computing dimensions: infrastructure as a service classification framework. System Science (HICSS), 2012 45th Hawaii International Conference (pp. 2178-2188). IEEE.

Rieger, P., Gewald, H. \& Schumacher, B. (2013). Cloud computing in Banking: influential factors, benefits and risks from a decision maker's perspective. Proceedings of the Nineteenth Americas Conference on Information Systems. Chicago, Illinois. 
Rochwerger, B. et al. (2009). The reservoir model and architecture for for open federated cloud computing, IBM Systems Journal and Development Archive, 53(4:1-4:11). IEEE.

Rogers, E. M. (2003). Diffusion of innovations. 5th ed. New York, NY, USA: The Free Press.

Sahin, I. (2006). Detailed review of Rogers' Diffusion of Innovations Theory and educational technology-related studies based on Rogers' Theory. The Turkish Online Journal of Educational Technology, 5(2), 14-23. 